\title{
Simultaneous quantification of major bioactive constituents from Zhuyeqing Liquor by HPLC-PDA
}

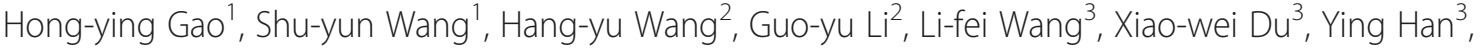 \\ Jian Huang ${ }^{2}$ and Jin-hui Wang ${ }^{1,2^{*}}$
}

\begin{abstract}
Background: Zhuyeqing Liquor (ZYQL) is a famous traditional Chinese functional liquor. For quality control of ZYQL products, quantitative analysis using high-performance liquid chromatography coupled with photodiode array detector (HPLC-PDA) was undertaken.

Methods: Eighteen compounds from ZYQL were simultaneously detected and used as chemical markers in the quantitative analysis, including 3-hydroxy-4,5(R)-dimethyl-2(5H)-furanone (M1), isobiflorin (M2), vanillic acid (M3), biflorin (M4), genipin 1-O- $\beta$-D-gentiobioside (M5), 1-sinapoyl- $\beta$-D-glucopyranoside (M6), geniposide (M7), epijasmnoside A (M8), ferulic acid (M9), luteolin 8-C- $\beta$-glucopyranoside (M10), isoorientin (M11), narirutin (M12), hesperidin (M13), 6'-O-sinapoylgeniposide (M14), 3,5-dihydroxy-3',4',7,8-tetramethoxyl flavones (M15), 3',4',3,5,6,8-hexamethoxyl flavone (M16), kaempferide (M17), and tangeretin (M18).

Results: The separation by gradient elution was achieved on SHIMADZU VP-ODS column $(4.6 \times 150 \mathrm{~mm}, 5 \mu \mathrm{m})$ at $30^{\circ} \mathrm{C}$ with methanol (A)/0.1\% phosphoric acid (B) as the mobile phase. The detection wavelengths were 254,278 , and $335 \mathrm{~nm}$. The optimized HPLC method provided a good linear relation ( $r \geq 0.9991$ for all the target compounds), satisfactory precision (RSD values less than $1.47 \%$ ) and good recovery (97.40\% to $103.44 \%$ ). The limits of detection ranged between $0.20 \times 10^{-4}$ and $64.90 \times 10^{-4} \mathrm{\mu g} / \mathrm{\mu L}$ for the different analytes. Furthermore, the optimum sample preparation was obtained from HPD 100 column eluted with water and $95 \%$ ethanol, respectively.
\end{abstract}

Conclusions: Quality control of ZYQL products, in total seven samples and twelve parent plants, was examined by this method, and results confirmed its feasibility and reliability in practice.

Keywords: Zhuyeqing Liquor; Bioactive constituent; Quantitative analysis; HPLC-PDA

\section{Background}

Zhuyeqing Liquor (ZYQL), authorized as a functional health liquor in 1998 by the Ministry of Public Health in China, is a famous traditional Chinese functional liquor. The history of ZYQL could be traced back to the Warring States Period and became popular among people in the South and North Dynasties. In the Tang Dyansty and Song Dynasty, it had reached its climax (Yang 2007). ZYQL was designed based on the principles of traditional Chinese medicine (TCM) and comprises 12 herbs: Lophatherum gracile Brongn. (Zhuye), Gardenia jasminoides Ellis (Zhizi),

\footnotetext{
* Correspondence: wjh.1972@aliyun.com

'School of Traditional Chinese Materia Medica 49\#, Shenyang Pharmaceutical University, Wenhua Road 103, Shenyang 110016, People's Republic of China ${ }^{2}$ School of Pharmacy, Shihezi University, Shihezi 832002, People's Republic of China

Full list of author information is available at the end of the article
}

Lysimachia capillipes Hemsl. (Paicao), Angelica sinensis (Oliv.) Diels (Danggui), Kaempferia galanga L. (Shannai), Citrus reticulata Blanco (Chenpi), Chrysanthemum morifolium Ramat. (Juhua), Amomum villosum Lour. (Sharen), Santalum album L. (Tanxiang), Eugenia caryophyllata Thunb. (Gongdingxiang), Aucklandia lappa Decne. (Guangmuxiang), and Lysimachia foenum-graecum Hance (Linglingxiang). According to its long-term history use, ZYQL has various biological properties such as anti-oxidant, anti-fatigue, and immunoenhancement (Han 2007).

Up to now, many studies show solicitude for the color, smell, and taste of the health functional liquor; few studies pay close attention to its chemical constituents and quality control. Currently, chemical analytical methods for the quality control of ZYQL have not been established. Therefore, it is necessary to establish a rapid and effective method 
for the quantitative analysis of the health functional liquor. In this study, the system of high-performance liquid chromatography coupled with photodiode array detector (HPLC-PDA) was used for analyzing the chemical profile of ZYQL. This method includes many advantages like high speed detection, excellent peak shapes, less solvent usage, well-defined chemical constituents, and simultaneous detection of multi-constituents, which is better than fingerprinting. Thus, simultaneous determination by RP-HPLC method is suitable for quantitative analysis and can be used as an effective tool to evaluate herbal medicine products.

\section{Methods}

\section{Chemicals and materials}

Methanol (HPLC-grade) was purchased from Fisher Scientific Co. (Franklin, MA, USA). Water for HPLC analysis was purified by a Milli-Q water purification system (Millipore, Billerica, MA, USA). Phosphoric acid (analytical grade) was purchased from Tianjin Guangfu Chemical Reagent Co. Ltd. (Tianjin, China). Other solvents from Tianjin Guangfu Chemical Reagent Co. Ltd. (Tianjin, China) were all of analytical grade.

Reference compounds of M1 to M18 (Figure 1) were isolated previously from ZYQL by author, structures of which were elucidated by comparison of spectral data (UV, MS, ${ }^{1} \mathrm{H}$ NMR, and ${ }^{13} \mathrm{C}$ NMR) with the literature data (Lin et al. 2006; Okamura et al. 1998; Huang et al. 2012; Zhang and Chen 1997; Ma et al. 2009; Miyake et al. 2007; Liu et al. 2011; Chen et al. 2008; Rayyan et al. 2005; Kumarasamy et al. 2004; Ke et al. 1999; Yoo et al. 2002; Dinda et al. 2011; Esteban et al. 1986; Ballester et al. 2013; Wang et al. 2010; Hòrie et al. 1998). The purity of each reference standard<smiles>CC1OC(=O)C(O)=C1F</smiles>

1<smiles>COc1ccc(C(=O)O)cc1</smiles><smiles>[R3]c1c([R3])c(O)c2c(=O)cc(C)oc2c1[Y]</smiles>

$2 \mathrm{R}_{1}=$ bait-D-glucosyl, $\mathrm{R}_{2}=\mathrm{OH}, \mathrm{R}_{3}=\mathrm{H}$ $4 \mathrm{R}_{1}=\mathrm{H}, \mathrm{R}_{2}=\mathrm{OH}, \mathrm{R}_{3}=$ bait-D-glucosyl

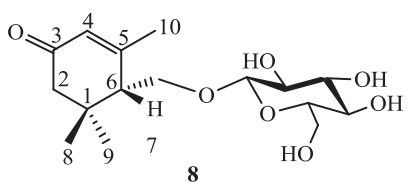

8

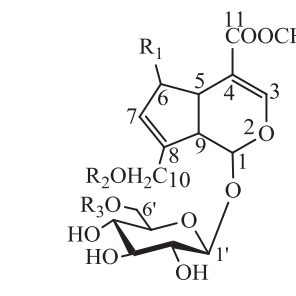

$5 \mathrm{R}_{1}=\mathrm{H}, \mathrm{R}_{2}=\mathrm{H}, \mathrm{R}_{3}=$ bait-D-glucosyl $7 \mathrm{R}_{1}=\mathrm{H}, \mathrm{R}_{2}=\mathrm{H}, \mathrm{R}_{3}=\mathrm{H}$ $14 \mathrm{R}_{1}=\mathrm{H}, \mathrm{R}_{2}=\mathrm{H}, \mathrm{R}_{3}=$ trans-sinapoyl<smiles>[R]c1ccc(-c2oc3c([R])c([R])c([R])c([R])c3c(=O)c2O)cc1[R]</smiles>

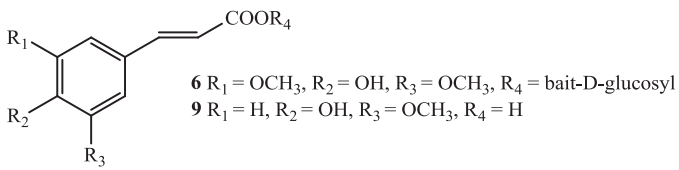

$15 \mathrm{R}_{1}=\mathrm{OCH}_{3}, \mathrm{R}_{2}=\mathrm{OCH}_{3}, \mathrm{R}_{3}=\mathrm{H}, \mathrm{R}_{4}=\mathrm{OH}, \mathrm{R}_{5}=\mathrm{H}, \mathrm{R}_{6}=\mathrm{OCH}_{3}, \mathrm{R}_{7}=\mathrm{OCH}_{3}$ $16 \mathrm{R}_{1}=\mathrm{OCH}_{3}, \mathrm{R}_{2}=\mathrm{H}, \mathrm{R}_{3}=\mathrm{OCH}_{3}, \mathrm{R}_{4}=\mathrm{OCH}_{3}, \mathrm{R}_{5}=\mathrm{OCH}_{3}, \mathrm{R}_{6}=\mathrm{OCH}_{3}, \mathrm{R}_{7}=\mathrm{OCH}_{3}$ $17 \mathrm{R}_{1}=\mathrm{H}, \mathrm{R}_{2}=\mathrm{OH}, \mathrm{R}_{3}=\mathrm{H}, \mathrm{R}_{4}=\mathrm{OH}, \mathrm{R}_{5}=\mathrm{H}, \mathrm{R}_{6}=\mathrm{H}, \mathrm{R}_{7}=\mathrm{OCH}_{3}$<smiles>[R3]c1ccc(-c2cc(=O)c3c([R3])c([R3])c([R])c([R])c3o2)cc1Br</smiles>

$10 \mathrm{R}_{1}=$ bait-D-glucosyl, $\mathrm{R}_{2}=\mathrm{OH}, \mathrm{R}_{3}=\mathrm{H}, \mathrm{R}_{4}=\mathrm{OH}, \mathrm{R}_{5}=\mathrm{OH}, \mathrm{R}_{6}=\mathrm{OH}$ $1 \mathrm{R}_{1}=\mathrm{H}, \mathrm{R}_{2}=\mathrm{OH}, \mathrm{R}_{3}=$ bait-D-glucosyl, $\mathrm{R}_{4}=\mathrm{OH}, \mathrm{R}_{5}=\mathrm{OH}, \mathrm{R}_{6}=\mathrm{OH}$ $8 \mathrm{R}_{1}=\mathrm{OCH}_{3}, \mathrm{R}_{2}=\mathrm{OCH}_{3}, \mathrm{R}_{3}=\mathrm{OCH}_{3}, \mathrm{R}_{4}=\mathrm{OCH}_{3}, \mathrm{R}_{5}=\mathrm{H}, \mathrm{R}_{6}=\mathrm{OCH}_{3}$

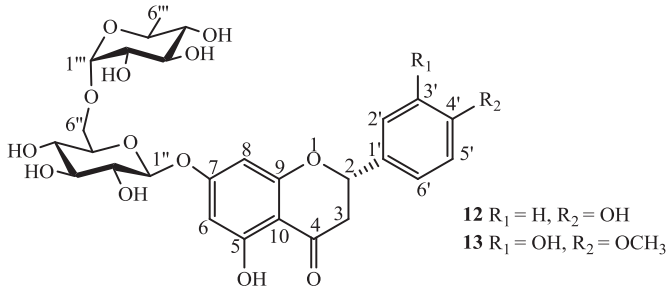

Figure 1 Structures of compounds M1 to M18. 
was determined to be above $98 \%$ by HPLC analysis based on a peak area normalization method, detected by HPLC-PDA and confirmed by HR-ESI-TOF-MS and NMR spectroscopy.

The samples of different batch and different alcoholicity of ZYQL and the 12 parent plants were provided by Shanxi XinghuaCun Fen Jiu Group Co., Ltd. (Shanxi, China). The 12 parent plants were identified by Professor Jincai Lu (Shenyang Pharmaceutical University, Shenyang, China). The voucher specimen was deposited at Shenyang Pharmaceutical University (Shenyang, China) and registered under the number ZYQL 2011050101.

\section{Instrumentation and chromatographic conditions}

Chromatographic analysis was performed on Waters 2695 Alliance HPLC system (Waters Co., Milford, MA, USA) with Waters 2998 PDA detector. Chromatographic separation was carried on a SHIMADZU VP-ODS column (4.6 mm $\times 150 \mathrm{~mm}, 5 \mu \mathrm{m}$; Shimadzu, Kyoto, Japan) at a column temperature of $30^{\circ} \mathrm{C}$ using methanol (A) and $0.1 \%$ phosphoric acid (B) as mobile phase with the gradient elution procedure show in Table 1 . The flow rate was set at $1.0 \mathrm{ml} / \mathrm{min}$ and the detection wavelengths were $254 \mathrm{~nm}$ (for compounds M1 to M5, M7, M8, and M17), $278 \mathrm{~nm}$ (for compounds M12 and M13), and $335 \mathrm{~nm}$ (for compounds M6, M9 to M11, M14 to M16, and M18), which were chosen based on the maximum absorption of all the tested compounds. The injection volume was $10 \mu \mathrm{L}$, and the analytes were well separated in chromatographic conditions above.

\section{Standard solution preparation}

Individual stock solutions were prepared by dissolving the standards in methanol to obtain 3-hydroxy-4,5(R)-dimethyl-2(5H)-furanone (M1) $19.920 \mathrm{mg} \mathrm{mL}^{-1}$, isobiflorin (M2) $8.330 \mathrm{mg} \mathrm{mL}^{-1}$, vanillic acid (M3) $5.802 \mathrm{mg} \mathrm{mL}^{-1}$, biflorin (M4) $3.911 \mathrm{mg} \mathrm{mL}^{-1}$, genipin 1-O- $\beta$-D-gentiobioside (M5) $4.405 \mathrm{mg} \mathrm{mL}^{-1}$, 1-sinapoyl- $\beta$-D-glucopyranoside (M6) $1.115 \mathrm{mg} \mathrm{mL}^{-1}$, geniposide (M7) $23.804 \mathrm{mg} \mathrm{mL}^{-1}$, epijasmnoside A (M8) $12.060 \mathrm{mg} \mathrm{mL}^{-1}$, ferulic acid (M9) $2.515 \mathrm{mg} \mathrm{mL}^{-1}$, luteolin 8-C- $\beta$-glucopyranoside (M10) $1.510 \mathrm{mg} \mathrm{mL}^{-1}$, isoorientin (M11) $2.203 \mathrm{mg} \mathrm{mL}^{-1}$, nairutin (M12) $1.032 \mathrm{mg} \mathrm{mL}^{-1}$, hesperidin (M13) $4.801 \mathrm{mg} \mathrm{mL}^{-1}$,

Table 1 Time program of the gradient elution

\begin{tabular}{lccc}
\hline Time (min) & Flow (mL/min) & Methanol (\%) & $\begin{array}{c}\mathbf{0 . 1 \%} \text { Phosphatic } \\
\text { acid (\%) }\end{array}$ \\
\hline 0 & 1 & 5 & 95 \\
70 & 1 & 55 & 45 \\
75 & 1 & 60 & 40 \\
110 & 1 & 80 & 20 \\
120 & 1 & 98 & 2 \\
125 & 1 & 98 & 2 \\
\hline
\end{tabular}

6'-O-sinapoylgeniposide (M14) $5.312 \mathrm{mg} \mathrm{mL}^{-1}$, 3,5-dihydroxy-3',4',7,8-tetramethoxyl flavones (M15) $5.021 \mathrm{mg}$ $\mathrm{mL}^{-1}, 3^{\prime}, 4^{\prime}, 3,5,6,8$-hexamethoxyl flavone (M16) $15.005 \mathrm{mg}$ $\mathrm{mL}^{-1}$, kaempferide (M17) $6.408 \mathrm{mg} \mathrm{mL}^{-1}$, and tangeretin (M18) $17.155 \mathrm{mg} \mathrm{mL}^{-1}$. A mixed solution containing all the 18 standards was prepared as accurately as $108 \mu \mathrm{L} \mathrm{M1}$, $6.8 \mu \mathrm{L}$ M2, 2.4 $\mu \mathrm{L}$ M3, 8.0 $\mu \mathrm{L}$ M4, $165 \mu \mathrm{L}$ M5, $96 \mu \mathrm{L}$ M6, $106 \mu \mathrm{L}$ M7, 3.4 $\mu \mathrm{L}$ M8, $8.2 \mu \mathrm{L}$ M9, $9.5 \mu \mathrm{L}$ M10, $7.9 \mu \mathrm{L}$ M11, $35 \mu \mathrm{L}$ M12, $40 \mu \mathrm{L}$ M13, $80 \mu \mathrm{L}$ M14, $8.2 \mu \mathrm{L}$ M15, $11 \mu \mathrm{L}$ M16, $12 \mu \mathrm{L}$ M17, and $4.6 \mu \mathrm{L}$ M18 and were placed in a 2 -mL flask with stopper, diluted with methanol to make sure the volume reached $2 \mathrm{~mL}$. All prepared solutions were respectively stored in a refrigerator at $4^{\circ} \mathrm{C}$ when not in use.

\section{Treatment for samples}

For the analysis, $40 \mathrm{~mL}$ of $\mathrm{ZYQL}$ were evaporated in vacuum at $50^{\circ} \mathrm{C}$ to dryness. The dry residue was processed as follows in order to obtain better analytical results: The residue was dissolved with water $(10 \mathrm{~mL})$ and applied to an $\mathrm{HPD}_{100}$ column eluted with water $(150 \mathrm{~mL})$; the water eluent was discarded and then eluted with $95 \%$ ethanol $(150 \mathrm{~mL})$. The $95 \%$ ethanol eluent was condensed and dissolved with methanol and then placed in a 2-mL flask with stopper, with a methanol-metered volume. Prior to HPLC analysis, the sample solution was passed through a $0.22-\mu \mathrm{m}$ millipore filter.

The 12 crude dried parent plants were pulverized and sifted through 40 mesh sieve, respectively. One gram of the powder from the parent plant was placed in a 50-mL flask with stopper, then weighed again correctly, and extracted by ultrasonic method with $20 \mathrm{~mL}$ methanol for $30 \mathrm{~min}$. Then standing, it was cooled down to room temperature $\left(22^{\circ} \mathrm{C}\right)$ and the weight was mended to the incipient weight with methanol. Prior to HPLC analysis, the sample solution was passed through a $0.22-\mu \mathrm{m}$ millipore filter.

\section{Validation of the method Calibration curves}

Linearity was established by the injection of $1,2,4,8$, 12,16 , and $20 \mu \mathrm{L}$ of the mixed reference standard solution prepared, respectively. Calibration graphs were plotted subsequently based on linear regression analysis of the integrated peak $(Y)$ versus content $(X, \mu \mathrm{g})$.

\section{Limits of detection and quantitation}

In order to evaluate the limits of detection (LODs) and the limits of quantification (LOQs) of the compounds, mixed standard stock solution was further diluted serially to provide a series of appropriate concentrations, and an aliquot of the diluted solutions was injected into HPLC for analysis. The LOD and LOQ for each analyte was calculated with corresponding standard solution on the basis of a signal-to-noise ratio $(\mathrm{S} / \mathrm{N})$ of 3 and 10 , respectively. 


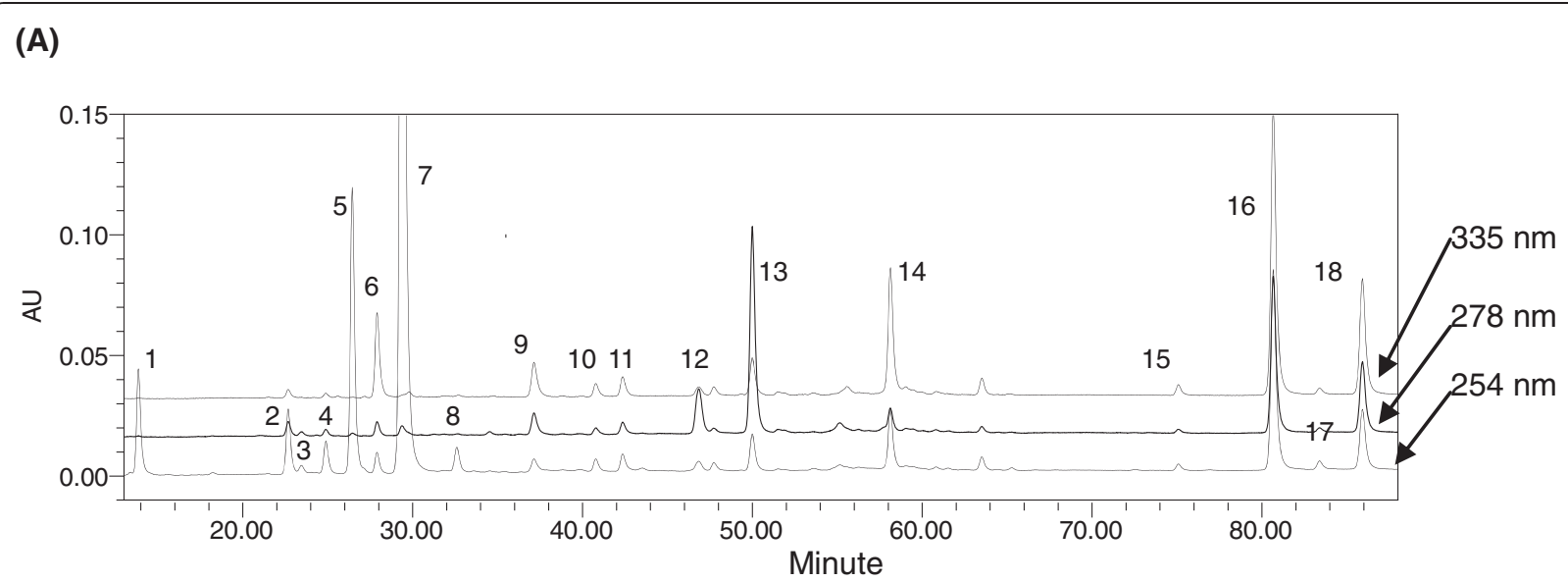

(B)
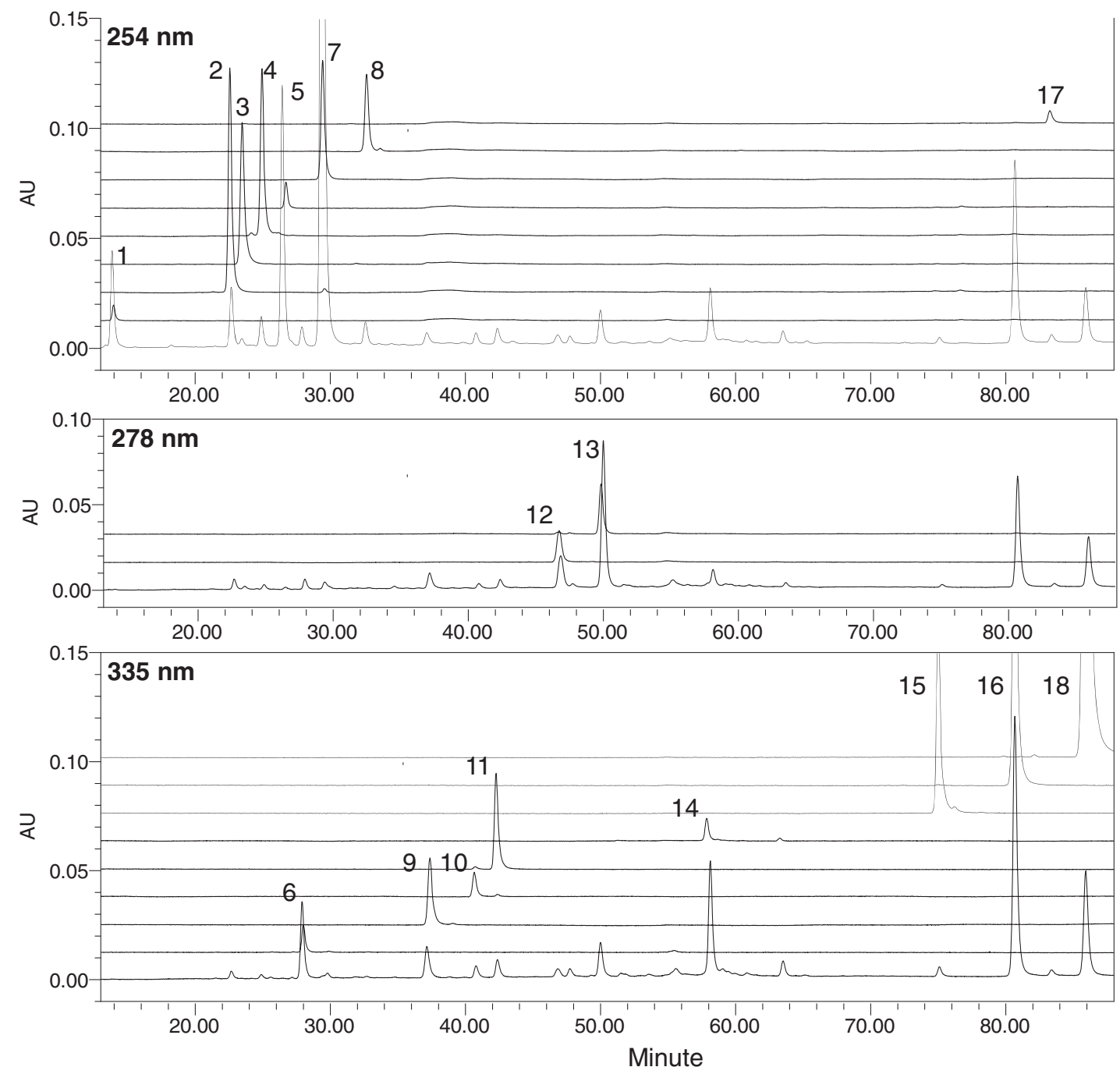

Figure 2 Stack views. (A) Different detector-wavelength HPLC chromatograms of mixed reference standards (from up to down: 335, 278, $254 \mathrm{~nm}$ ). Column: SHIMADZU VP-ODS column $(4.6 \mathrm{~mm} \times 150 \mathrm{~mm}, 5 \mu \mathrm{m})$, temperature of $30^{\circ} \mathrm{C}$. (B) HPLC chromatograms of $\mathbf{M} 1$ to $\mathbf{M} 18$ and mixed reference standards (from up to down: $254 \mathrm{~nm}$ M1, M2, M3, M4, M5, M7, M8, M17, mixed reference standards; $278 \mathrm{~nm}$ M12, M13, mixed reference standards; $335 \mathrm{~nm}$ M6, M9, M10, M11, M14, M15, M16, M18, mixed reference standards). 
Table 2 Optimization of the treatment method of Zhuyeqing Liquor $(\mu \mathrm{g} / \mathrm{mL})$

\begin{tabular}{|c|c|c|c|c|c|}
\hline \multirow[t]{2}{*}{ Compound $^{\mathrm{a}}$} & \multicolumn{5}{|c|}{ Treatment method } \\
\hline & Method 1 & Method 2 & Method 3 & Method 4 & Method 5 \\
\hline M1 & ND & 5.2494 & 3.1331 & 9.5943 & 16.4270 \\
\hline M2 & 0.0888 & 0.5371 & 0.5078 & 0.5818 & 0.5942 \\
\hline M3 & 0.0922 & 0.0906 & 0.0388 & 0.0939 & 0.1063 \\
\hline M4 & 0.0263 & 0.4980 & 0.5098 & 0.5069 & 0.5153 \\
\hline M5 & ND & 44.0545 & 101.6907 & 100.6372 & 101.7888 \\
\hline M6 & 0.1479 & 0.1880 & 0.1902 & 0.1927 & 0.1936 \\
\hline M7 & 45.2421 & 563.2436 & 570.3556 & 566.0022 & 574.2514 \\
\hline M8 & 20.8481 & 24.6279 & 25.6049 & 24.5513 & 25.7319 \\
\hline M9 & 0.1931 & 0.1782 & 0.1906 & 0.1918 & 0.1968 \\
\hline M10 & 0.0324 & 0.0526 & 0.0600 & 0.0705 & 0.0736 \\
\hline M11 & 0.2009 & 0.4601 & 0.4871 & 0.4915 & 0.4954 \\
\hline M12 & 0.7071 & 1.0544 & 1.0683 & 1.0699 & 1.0877 \\
\hline M13 & 1.1371 & 2.5392 & 2.8461 & 2.8029 & 2.9909 \\
\hline M14 & ND & 3.4939 & 4.0839 & 4.0563 & 4.3756 \\
\hline M15 & ND & 0.0641 & 0.0678 & 0.0688 & 0.0689 \\
\hline M16 & 0.5189 & 0.6113 & 0.5842 & 0.3282 & 0.6623 \\
\hline M17 & 2.9599 & 2.9776 & 2.1520 & 1.6446 & 2.9957 \\
\hline M18 & 0.4448 & 0.5307 & 0.4278 & 0.4673 & 0.5413 \\
\hline Sum ${ }^{b}$ & 72.6396 & 650.4512 & 713.9987 & 713.3521 & 733.0967 \\
\hline
\end{tabular}

Sample in optimization of the treatment method was $45^{\circ}$ Zhuyeqing Liquor (20130207). Method 1, acetoacetate extract; method 2, $n$-butanol extract; method 3, $70 \%$ ethanol treatment; method 4, SPE column eluted with methanol; method 5, HPD ${ }_{100}$ column eluted with ethanol. ${ }^{a}$ ND' in the 'Compound' column expressed under LOQ. ' ${ }^{\text {Total }}$ content of the 18 investigated compounds.

\section{Precision and stability}

The precision of the chromatographic system was validated by injecting $10 \mu \mathrm{L}$ of the mixed reference solution six times during 1 day. Stability study was performed with sample solution in $48 \mathrm{~h}$ (the time points are $0,5,10,15$, 25,35 , and $48 \mathrm{~h}$, respectively). Variations were expressed by relative standard deviations (RSD) of peak area.

\section{Repeatability and recovery}

The repeatability test was analyzed by injecting six independently prepared samples ( $45^{\circ} \mathrm{ZYQL}$ (20130207), the concentration, and prepared method as the 'Treatment for samples'). The RSD value of concentration was adopted to evaluate repeatability. The recovery tests were studied by adding the proper amount of mixed-reference standard

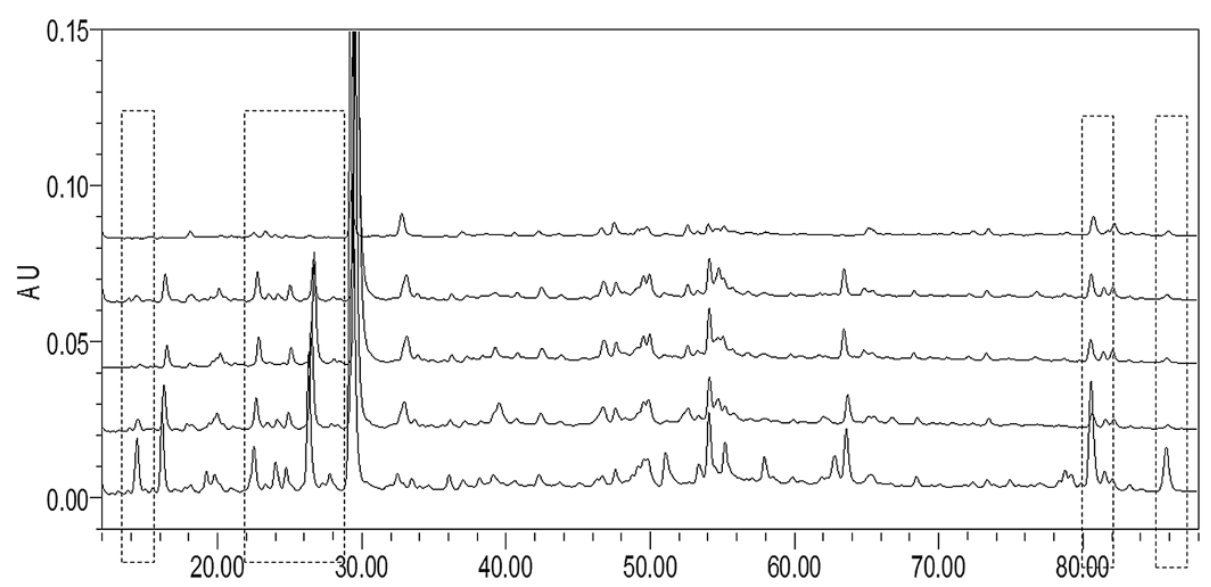

Figure 3 Stack views of $45^{\circ}$ Zhuyeqing Liquor preparation method HPLC chromatograms ( $254 \mathrm{~nm}$, from up to down: method 1, method 2, method 3, method 4 and method 5). 
Table 3 Regression equations, correlation coefficients, and linear range for 18 analytes in Zhuyeqing Liquor

\begin{tabular}{|c|c|c|c|c|c|c|}
\hline \multirow[t]{2}{*}{ Analyte } & \multirow{2}{*}{$\begin{array}{c}\text { Time } \\
\left(t_{\mathrm{R}}\right)\end{array}$} & \multicolumn{5}{|c|}{ Linear regression } \\
\hline & & Regression equation $(n=3)$ & $\begin{array}{c}\text { Correlation } \\
\text { coefficients } \\
r\end{array}$ & Linear range $(\mu \mathrm{g})$ & $\begin{array}{c}\text { LOD } \\
\left(10^{-4} \mu \mathrm{g} / \mu \mathrm{L}\right)\end{array}$ & $\begin{array}{c}\text { LOQ } \\
\left(10^{-4} \mu \mathrm{g} / \mu \mathrm{L}\right)\end{array}$ \\
\hline M1 & 14.004 & $Y=5.48 e+003 X-1.45 e+003$ & 0.9998 & $1.08 \sim 21.63$ & 64.90 & 216.34 \\
\hline M2 & 22.819 & $Y=2.86 e+006 X-8.84 e+002$ & 0.9999 & $2.80 \times 10^{-2} \sim 5.60 \times 10^{-1}$ & 1.68 & 5.60 \\
\hline M3 & 23.573 & $Y=4.73 e+006 X-5.52 e+003$ & 0.9991 & $1.70 \times 10^{-3} \sim 3.40 \times 10^{-2}$ & 0.20 & 0.67 \\
\hline M4 & 25.069 & $Y=1.62 e+006 X-3.23 e+003$ & 0.9997 & $1.55 \times 10^{-2} \sim 3.10 \times 10^{-1}$ & 3.10 & 10.34 \\
\hline M5 & 26.671 & $Y=5.41 e+005 X-3.44 e+004$ & 0.9994 & $3.63 \times 10^{-1} \sim 7.25$ & 2.42 & 8.08 \\
\hline M6 & 28.087 & $Y=1.31 e+006 X-4.70 e+003$ & 0.9998 & $5.25 \times 10^{-2} \sim 1.05$ & 8.40 & 28.0 \\
\hline M7 & 29.646 & $Y=7.08 e+005 X+4.19 e+003$ & 0.9998 & $1.26 \sim 25.21$ & 25.46 & 84.87 \\
\hline M8 & 32.875 & $Y=9.81 e+005 X-5.87 e+003$ & 0.9998 & $2.04 \times 10^{-2} \sim 4.08 \times 10^{-1}$ & 4.08 & 13.60 \\
\hline M9 & 37.264 & $Y=3.17 e+006 X-1.51 e+004$ & 0.9992 & $1.03 \times 10^{-2} \sim 2.06 \times 10^{-1}$ & 2.06 & 6.87 \\
\hline M10 & 40.883 & $Y=1.65 e+006 X-1.26 e+002$ & 0.9993 & $7.10 \times 10^{-3} \sim 1.42 \times 10^{-1}$ & 2.13 & 7.11 \\
\hline M11 & 42.396 & $Y=2.38 e+006 X-6.23 e+003$ & 0.9991 & $8.70 \times 10^{-3} \sim 1.74 \times 10^{-1}$ & 1.74 & 5.83 \\
\hline M12 & 46.878 & $Y=2.67 e+006 X-3.22 e+002$ & 0.9998 & $1.75 \times 10^{-2} \sim 3.50 \times 10^{-1}$ & 5.25 & 17.51 \\
\hline M13 & 50.008 & $Y=1.69 e+006 X+3.71 e+003$ & 0.9998 & $9.56 \times 10^{-2} \sim 1.91$ & 5.74 & 19.12 \\
\hline M14 & 58.096 & $Y=4.55 e+005 X-2.11 e+003$ & 0.9998 & $2.13 \times 10^{-1} \sim 4.25$ & 12.75 & 42.50 \\
\hline M15 & 74.987 & $Y=2.15 e+006 X-7.62 e+002$ & 0.9991 & $4.10 \times 10^{-3} \sim 8.20 \times 10^{-2}$ & 3.28 & 10.95 \\
\hline M16 & 80.609 & $Y=3.59 e+006 X-2.08 e+004$ & 0.9999 & $8.23 \times 10^{-2} \sim 1.65$ & 0.55 & 1.84 \\
\hline M17 & 83.248 & $Y=1.97 e+005 X-3.36 e+003$ & 0.9991 & $3.85 \times 10^{-2} \sim 7.70 \times 10^{-1}$ & 15.40 & 51.32 \\
\hline M18 & 85.890 & $Y=2.69 e+006 X-1.38 e+004$ & 0.9996 & $3.93 \times 10^{-2} \sim 7.86 \times 10^{-1}$ & 0.79 & 2.64 \\
\hline
\end{tabular}

$Y$ is the peak area and $X$ is the content of standard solutions; LOD refers to the limits of detection, $S / N=3 ; L O Q$ refers to the limits of quantity, $S / N=10$.

Table 4 Precision, stability, recovery, and repeatability data of 18 analytes in Zhuyeqing Liquor

\begin{tabular}{|c|c|c|c|c|c|c|c|c|c|c|}
\hline \multirow[t]{2}{*}{ Analyte } & \multicolumn{2}{|c|}{ Precision $(n=6)$} & \multirow{2}{*}{$\begin{array}{l}\text { Stability } \\
\text { RSD (\%) }\end{array}$} & \multicolumn{5}{|c|}{ Recovery $(n=6)$} & \multicolumn{2}{|c|}{ Repeatability $(n=6)$} \\
\hline & $\begin{array}{l}\text { Concentrations } \\
(\mathrm{mg} / \mathrm{mL})\end{array}$ & $\begin{array}{l}\text { RSD } \\
(\%)\end{array}$ & & $\begin{array}{c}\text { Original } \\
(\mu \mathrm{g})\end{array}$ & $\begin{array}{l}\text { Spiked } \\
(\mu \mathrm{g})\end{array}$ & $\begin{array}{l}\text { Detected } \\
(\mu \mathrm{g})\end{array}$ & $\begin{array}{c}\text { Recovery } \\
\text { (\%) }\end{array}$ & $\begin{array}{l}\text { RSD } \\
\text { (\%) }\end{array}$ & $\begin{array}{c}\text { Average } \\
\text { concentration } \\
(\mu \mathrm{g} / \mathrm{mL})\end{array}$ & $\begin{array}{l}\text { RSD } \\
\text { (\%) }\end{array}$ \\
\hline M1 & 1.08 & 0.92 & 1.70 & 164.16 & 162.26 & 326.57 & 100.17 & 3.10 & $16.0862 \pm 0.2722$ & 1.50 \\
\hline M2 & $2.80 \times 10^{-2}$ & 0.82 & 1.52 & 7.11 & 4.20 & 11.41 & 102.44 & 1.84 & $0.5580 \pm 0.0045$ & 1.39 \\
\hline M3 & $1.70 \times 10^{-3}$ & 1.30 & 1.66 & 0.27 & 0.26 & 0.52 & 97.40 & 2.52 & $0.1072 \pm 0.0020$ & 1.96 \\
\hline M4 & $1.55 \times 10^{-2}$ & 0.78 & 1.08 & 5.88 & 2.33 & 8.23 & 100.88 & 2.27 & $0.5154 \pm 0.0032$ & 0.64 \\
\hline M5 & $3.63 \times 10^{-1}$ & 0.87 & 1.62 & 1217.80 & 54.39 & 1273.19 & 101.83 & 3.30 & $101.1963 \pm 0.7206$ & 0.72 \\
\hline M6 & $5.25 \times 10^{-2}$ & 0.86 & 1.58 & 6.00 & 7.88 & 14.15 & 103.44 & 1.68 & $0.1940 \pm 0.0019$ & 1.00 \\
\hline M7 & 1.26 & 0.49 & 1.18 & 1270.60 & 1260.30 & 2543.54 & 101.00 & 0.78 & $568.4991 \pm 2.7722$ & 0.98 \\
\hline M8 & $2.04 \times 10^{-2}$ & 1.04 & 1.76 & 211.50 & 102.00 & 316.34 & 102.79 & 1.46 & $25.1942 \pm 0.2548$ & 1.45 \\
\hline M9 & $1.03 \times 10^{-2}$ & 0.30 & 1.49 & 2.82 & 1.55 & 4.37 & 100.76 & 2.63 & $0.1947 \pm 0.0018$ & 1.00 \\
\hline M10 & $7.10 \times 10^{-3}$ & 1.10 & 1.67 & 3.22 & 1.07 & 4.28 & 99.54 & 3.26 & $0.0728 \pm 0.0011$ & 1.61 \\
\hline M11 & $8.70 \times 10^{-3}$ & 1.15 & 1.62 & 4.65 & 1.31 & 5.96 & 100.66 & 3.09 & $0.5101 \pm 0.0057$ & 1.28 \\
\hline $\mathrm{M} 12$ & $1.75 \times 10^{-2}$ & 1.09 & 1.39 & 2.43 & 2.63 & 5.14 & 103.13 & 1.48 & $1.0800 \pm 0.0155$ & 1.44 \\
\hline M13 & $9.56 \times 10^{-2}$ & 1.02 & 1.36 & 37.69 & 14.34 & 52.20 & 101.14 & 1.99 & $2.8911 \pm 0.0351$ & 1.21 \\
\hline M14 & $2.13 \times 10^{-1}$ & 0.74 & 1.59 & 943.73 & 31.88 & 975.00 & 98.10 & 2.25 & $4.2790 \pm 0.0314$ & 1.30 \\
\hline M15 & $4.10 \times 10^{-3}$ & 1.47 & 1.75 & 1.99 & 1.23 & 3.22 & 100.30 & 2.66 & $0.0645 \pm 0.0009$ & 1.53 \\
\hline M16 & $8.23 \times 10^{-2}$ & 0.91 & 1.58 & 21.52 & 12.35 & 33.77 & 99.20 & 2.44 & $0.6444 \pm 0.0052$ & 0.81 \\
\hline M17 & $3.85 \times 10^{-2}$ & 0.93 & 1.75 & 133.12 & 115.50 & 249.54 & 100.79 & 2.63 & $2.9457 \pm 0.0498$ & 1.36 \\
\hline M18 & $3.93 \times 10^{-2}$ & 1.11 & 1.49 & 10.02 & 11.79 & 21.89 & 100.65 & 1.58 & $0.5368 \pm 0.0060$ & 1.13 \\
\hline
\end{tabular}

RSD refers to relative standard deviation. Samples in stability, recovery, and repeatability methods were taken from $45^{\circ}$ Zhuyeqing Liquor (20130207). 
solution to the sample (45 $\mathrm{ZYQL}$ (20130207)), and then processed by the method described in the 'Treatment for samples' section to yield the final concentration. The experiment was repeated six times.

\section{Results and discussion}

\section{Optimization of chromatographic conditions}

To improve resolution and sensitivity of analysis but reduce analytical time, the following chromatographic conditions were optimized (Gao et al. 2013), including different mobile phase compositions (methanol, acetonitrile, and aqueous phosphatic acid of different concentrations), column temperature, and wavelength: To inhibit ionization of the acidic ingredients in the ZYQL sample, phosphatic acid was added in mobile phase. Two mobile phase systems, methanol-phosphatic acid aqueous solution and acetonitrilephosphatic acid aqueous solution, were examined, and then column temperatures at $25^{\circ} \mathrm{C}, 30^{\circ} \mathrm{C}, 40^{\circ} \mathrm{C}$, and $50^{\circ} \mathrm{C}$ were compared. A sensitive wavelength was determined by PDA with reference compounds. Present researches indicated that better separation and results were obtained using a mobile phase of water and methanol rather than water and acetonitrile. Therefore, in this work, the optimum resolution was achieved using methanol (A) and $0.1 \%$ phosphatic acid (B) as mobile phase, with a column temperature of $30^{\circ} \mathrm{C}$ at different detection wavelengths, which were described in 'Instrumentation and chromatographic conditions' section, with gradient elution (Table 1). All 18 standard analytes could be eluted with baseline separation in $90 \mathrm{~min}$. Representative chromatograms for the mixed reference standard and 18 standard compounds were shown in Figure 2A,B.

\section{Optimization of sample preparation}

In order to eliminate the water-soluble constituents and obtain the liposoluble constituents, the optimization of sample preparation was performed using $45^{\circ}$ ZYQL (20130207). Forty milliliters of ZYQL was evaporated in vacuum at $50^{\circ} \mathrm{C}$ to dryness. And the following five methods were choosen to select the best method for sample preparation. First, the dry residue was suspended with water $(10 \mathrm{~mL})$ and extracted with acetoacetate $(10 \mathrm{~mL})$. The acetoacetate extract was condensed and then methanol was used to meter the volume

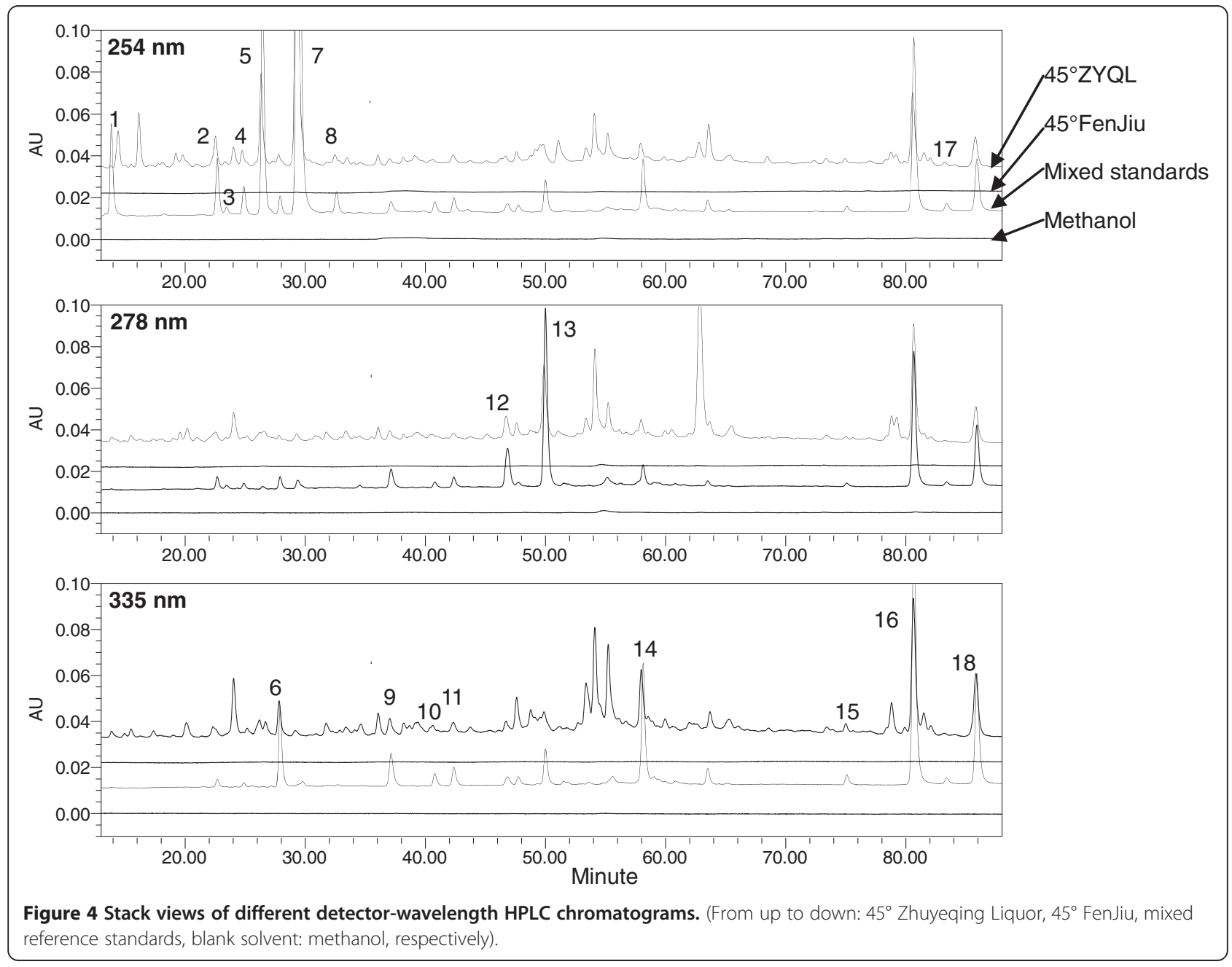


(2 mL). Second, the dry residue was suspended with water $(10 \mathrm{~mL})$ and extracted with $n$-butanol $(10 \mathrm{~mL})$ The $n$-butanol extract was condensed and then methanol was used to meter the volume $(2 \mathrm{~mL})$. Third, the dry residues was dissolved with $70 \%$ ethanol $(20 \mathrm{~mL})$ to precipitate the polysaccharide and then condensed the supernate, use methanol to metered volume $(2 \mathrm{~mL})$. Fourth, the dry residues was dissolved with water $(10 \mathrm{~mL})$ as fraction $\mathrm{A}$, then the remanent residues was dissolved with methanol $(10 \mathrm{~mL})$ as fraction $\mathrm{B}$. Fraction A was applied to an SPE column eluted with water (150 mL); the water eluent was discarded; fraction B was applied to the same SPE column eluted with methanol $(150 \mathrm{~mL})$; the methanol eluent was condensed and methanol was used to meter the volume $(2 \mathrm{~mL})$. Fifth, the dry residue was dissolved with water $(10 \mathrm{~mL})$ and applied to an $\mathrm{HPD}_{100}$ column eluted with water $(150 \mathrm{~mL})$. The water eluent was discarded and then eluted with $95 \%$ ethanol $(150 \mathrm{~mL})$. The 95\% ethanol eluent was condensed and then methanol was used to meter the volume $(2 \mathrm{~mL})$. Comparing the analytical results of the target constituents, though the former three methods proved to be more simple than the other, they could not obtain all the tested constituents and some content too lower to accurately reflect the real content. So, these three methods were deserted. The fourth one although could obtain all the tested constituents but at a lower content. Therefore, the optimized condition was selected, the fifth one (Table 2, Figure 3).

\section{Validation of the method}

The method was validated in terms of linearity, LOD and LOQ, precision, repeatability, stability, and recovery test. All calibration curves exhibited good linearity $(r \geq 0.9991)$ in a relatively wide linear range as shown in Table 3 . For the quantified compounds, the LOD and LOQ were $0.20 \times 10^{-4} \sim 64.90 \times 10^{-4} \mu \mathrm{g} / \mu \mathrm{L}$ and $0.67 \times 10^{-4} \sim 216.34 \times$ $10^{-4} \mu \mathrm{g} / \mu \mathrm{L}$, respectively (Table 3 ), which were calculated with corresponding standard solution on the basic of a signal-to-noise ratio $(\mathrm{S} / \mathrm{N})$ of 3 and 10 , respectively. Table 4 showed the results of precision, stability, recovery and repeatability of the 18 analytes. It was indicated that the RSD of the precision variations were less than $1.47 \%$ for all 18 analytes. The RSD of repeatability was less than $1.96 \%$ for all the analysis, which proved that this assay had good reproducibility. Stability test results, with RSD less than $1.76 \%$, indicated that the sample solution was stable at room temperature for at least $48 \mathrm{~h}$. The mean recovery rates, which ranged from $97.40 \%$ to $103.44 \%$ with RSD values less than $3.30 \%$ for the analytes concerned, showed that the developed analytical method had good accuracy. All these values fall within acceptable limits, which indicates this HPLC method is reliable with significant repeatability, recovery rate, and precision. The results proved that HPLC is appropriate for analyzing and assessing the quality of ZYQL.

Table 5 Contents of 18 analytes in different batches and different alcoholicity of Zhuyeqing Liquor $(\mu \mathrm{g} / \mathrm{mL}$ )

\begin{tabular}{|c|c|c|c|c|c|c|c|c|}
\hline \multirow[t]{2}{*}{ Compound $^{a}$} & \multirow{2}{*}{$\begin{array}{l}45^{\circ} \text { FenJiu } \\
20130207\end{array}$} & \multirow{2}{*}{$\begin{array}{l}38^{\circ} \\
20130207\end{array}$} & \multirow{2}{*}{$\begin{array}{l}42^{\circ} \\
20130207\end{array}$} & \multicolumn{5}{|l|}{$45^{\circ}$} \\
\hline & & & & 20130207 & 20120601 & 20110507 & 20100417 & 20090302 \\
\hline M1 & ND & 15.1395 & 15.1395 & 16.7150 & 16.6674 & 16.6558 & 16.6543 & 16.6239 \\
\hline M2 & ND & 0.3689 & 0.3945 & 0.5851 & 0.5854 & 0.5846 & 0.5839 & 0.5840 \\
\hline M3 & ND & 0.0792 & 0.0830 & 0.1063 & 0.1064 & 0.1058 & 0.1032 & 0.1060 \\
\hline M4 & ND & 0.3028 & 0.3742 & 0.5180 & 0.5139 & 0.5106 & 0.5081 & 0.5111 \\
\hline M5 & ND & 65.7206 & 71.8348 & 101.7175 & 101.3777 & 101.0265 & 101.1293 & 100.9297 \\
\hline M6 & ND & ND & ND & 0.1930 & 0.1904 & 0.1901 & 0.1893 & 0.1934 \\
\hline M7 & ND & 273.1958 & 309.9846 & 574.4770 & 574.1508 & 574.1103 & 573.6367 & 573.2887 \\
\hline M8 & ND & 12.6644 & 19.9230 & 25.8595 & 25.4397 & 25.2009 & 25.4234 & 25.1453 \\
\hline M9 & ND & 0.1395 & 0.1659 & 0.1956 & 0.1934 & 0.1909 & 0.1933 & 0.1938 \\
\hline M10 & ND & 0.0536 & 0.0612 & 0.0715 & 0.0714 & 0.0715 & 0.0715 & 0.0721 \\
\hline M11 & ND & 0.2612 & 0.2963 & 0.4993 & 0.4972 & 0.4983 & 0.4919 & 0.5000 \\
\hline M12 & ND & 0.5690 & 0.6861 & 1.0884 & 1.0835 & 1.0822 & 1.0806 & 1.0830 \\
\hline M13 & ND & 2.0079 & 2.0709 & 2.9740 & 2.9731 & 2.9587 & 2.8982 & 2.9883 \\
\hline M14 & ND & 2.5058 & 2.7162 & 4.3718 & 4.3672 & 4.3615 & 4.3586 & 4.3699 \\
\hline M15 & ND & 0.0549 & 0.0585 & 0.0689 & 0.0686 & 0.0684 & 0.0685 & 0.0686 \\
\hline M16 & ND & 0.4758 & 0.5602 & 0.6434 & 0.6435 & 0.6422 & 0.6427 & 0.6383 \\
\hline M17 & ND & 2.6999 & 2.8338 & 3.0047 & 2.9943 & 2.9927 & 2.9836 & 2.9735 \\
\hline M18 & ND & 0.3534 & 0.4045 & 0.5495 & 0.5432 & 0.5427 & 0.5389 & 0.5433 \\
\hline Sumb & ND & 376.5922 & 427.5872 & 733.6385 & 732.4671 & 731.7937 & 731.5560 & 730.8129 \\
\hline
\end{tabular}

${ }^{\mathrm{a}} \mathrm{ND}^{\prime}$ in the 'Compound' column expressed under LOQ. ${ }^{\mathrm{b}}$ Total content of the 18 investigated compounds. 
Table 6 Contents of 18 analytes in 12 parent plants $(\mathrm{mg} / \mathrm{g})$

\begin{tabular}{|c|c|c|c|c|c|c|c|c|c|c|c|c|}
\hline Compound $^{\mathrm{a}}$ & Zhuye & Zhizi & Paicao & Danggui & Shannai & Chenpi & Juhua & Sharen & Tanxiang & Gongdingxiang & Guangmuxiang & Linglingxiang \\
\hline M1 & ND & 2.1057 & ND & ND & ND & ND & ND & ND & ND & ND & ND & 19.8802 \\
\hline M2 & ND & ND & ND & ND & ND & ND & ND & ND & ND & 4.7841 & ND & 0.0790 \\
\hline M3 & ND & ND & ND & ND & ND & ND & ND & ND & 0.0038 & ND & ND & ND \\
\hline M4 & ND & ND & ND & ND & ND & ND & ND & ND & ND & 5.4547 & ND & 0.0498 \\
\hline M5 & ND & 19.9996 & ND & ND & ND & ND & ND & ND & ND & ND & ND & ND \\
\hline M6 & ND & 1.6513 & ND & ND & ND & 0.2580 & ND & ND & ND & ND & ND & ND \\
\hline M7 & ND & 43.3886 & ND & 2.5174 & ND & ND & ND & ND & ND & ND & ND & ND \\
\hline M8 & ND & 5.0078 & ND & ND & ND & 1.0468 & ND & ND & ND & ND & ND & ND \\
\hline M9 & ND & ND & ND & 0.6170 & ND & 0.0805 & ND & ND & ND & ND & ND & ND \\
\hline M10 & 0.3268 & ND & ND & ND & ND & ND & ND & ND & ND & ND & ND & ND \\
\hline M11 & 0.4161 & ND & ND & ND & ND & ND & ND & ND & ND & ND & ND & ND \\
\hline M12 & ND & 0.0111 & ND & ND & ND & 3.6198 & 0.2104 & ND & ND & ND & 0.0217 & ND \\
\hline M13 & ND & ND & ND & ND & ND & 4.6719 & 0.3139 & ND & ND & ND & ND & ND \\
\hline M14 & ND & 8.6950 & 0.0302 & ND & ND & ND & ND & 0.0292 & 0.0025 & $N D$ & ND & ND \\
\hline M15 & ND & ND & ND & ND & ND & 0.1017 & 0.0472 & ND & ND & ND & ND & ND \\
\hline M16 & 0.0638 & 0.0750 & ND & 0.2479 & 17.7933 & 0.6813 & 0.4755 & ND & ND & ND & ND & 0.3214 \\
\hline M17 & ND & 1.9330 & ND & ND & ND & 0.8970 & 1.4942 & ND & ND & ND & ND & ND \\
\hline M18 & ND & 0.0648 & ND & ND & ND & 0.5263 & 0.1625 & ND & ND & ND & ND & ND \\
\hline Sum ${ }^{b}$ & 0.8067 & 82.9319 & 0.0302 & 3.3823 & 17.7933 & 11.8833 & 2.7037 & 0.0292 & 0.0063 & 10.2388 & 0.0217 & 20.3304 \\
\hline
\end{tabular}

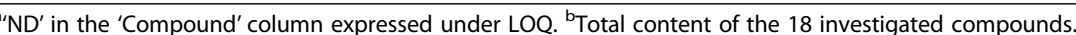




\section{Sample analysis}

The HPLC analytical method described above was subsequently used to simultaneously quantify 18 compounds in seven commercial products and 12 parent plants supplied by Shanxi XinghuaCun Fen Wine Group Co., Ltd. (Shanxi, China). Generally, the 18 compounds were authenticated by comparison of their retention times and MS spectra with those of reference standards. The representative HPLC chromatograms of mixed standard solution and sample solutions are shown in Figure 4. The analytical results are summarized in Tables 5 and 6 . According to the chromatographic results shown in Table 5, there was no any constituents to be detected in $45^{\circ}$ Fenjiu (solvent of ZYQL). Moreover, the concentration of compounds M1 to $\mathrm{M} 18$ in $45^{\circ} \mathrm{ZYQL}$ were higher than those in $42^{\circ}$ and $38^{\circ}$, which showed that with the increase of alcoholicity, the content of bioactive constituents increased as well. In addition, there was no content difference between the successive 5 years of $45^{\circ} \mathrm{ZYQL}$. This indicated that the quality of $45^{\circ} \mathrm{ZYQL}$ was stable for at least 5 years.

Table 6 showed the content of compounds in 12 parent plants, which exhibited that the major bioactive constituents were mainly from Gardenia jasminoides Ellis (Zhizi), Kaempferia galanga L. (Shannai), Citrus reticulata Blanco (Chenpi), and Lysimachia foenum-graecum Hance (Linglingxiang). And this result was greatly useful and helpful for the quality control and further formula optimization of the technical study of Zhuyeqing Liquor.

\section{Conclusions}

An HPLC-PDA method has been developed for the simultaneous determination of 18 major compounds extracted from ZYQL for the first time. The validation data indicated that this method is reliable and can be applied to determine the contents of the 18 compounds in different ZYQL products. This valuable information concerning the concentration of these bioactive constituents in ZYQL could be of great importance for the quality assessment and should therefore be useful for the guidance of development of the new health care products. Furthermore, this HPLC-PDA assay supplies a rapidness and effectiveness method for the simultaneous determination of multiple constituents in ZYQL.

\section{Competing interests}

The authors declare that they have no competing interests.

\section{Authors' contributions}

HYG carried out the whole experiment, SYW participated in the sample preparation, HYG and JHW performed the statistical analysis and drafted the manuscript. All authors read and approved the final manuscript.

\section{Acknowledgements}

Grateful acknowledgement is made to the Shanxi XinghuaCun Fen Jiu Group Co., Ltd. (Shanxi Province, China) and National Key Technology R\&D Program (2012BAl30B02) for financial support of this work. The authors acknowledge Waters Co. Ltd. for Cooperation Laboratory.

\section{Author details}

${ }^{1}$ School of Traditional Chinese Materia Medica 49\#, Shenyang Pharmaceutical University, Wenhua Road 103, Shenyang 110016, People's Republic of China. ${ }^{2}$ School of Pharmacy, Shihezi University, Shihezi 832002, People's Republic of China. ${ }^{3}$ Shanxi Xinghuacun Fen Jiu Group Co., Ltd, Shanxi 450000, People's Republic of China.

Received: 19 December 2013 Accepted: 12 June 2014

Published online: 08 August 2014

\section{References}

Ballester AR, Lafuente MT, De Vos RCH, Bovy AG, González-Candelas L (2013) Citrus phenylpropanoids and defence against pathogens. Part I: metabolic profiling in elicited fruits. Food Chem 136:178-185

Chen QC, Youn UJ, Min BS, Bae KH (2008) Pyronane monoterpenoids from the fruit of Gardenia jasminoides. J Nat Prod 71:995-999

Dinda B, Debnath S, Banik R (2011) Naturally occurring iridoids and secoiridoids. An updated review, part 4. Chem Pharm Bull 59:803-833

Esteban MD, González Collado L, Macías FA, Massanet GM, Rodríguez Luis F (1986) Flavonoids from Artemisia lanata. Phytochemistry 25:1502-1504

Gao HY, Huang J, Wang HY, Du XW, Cheng SM, Han Y, Wang LF, Li GY, Wang JH (2013) Protective effect of Zhuyeqing liquor, a Chinese traditional health liquor, on acute alcohol-induced liver injury in mice. J Inflamm 10:30

Han Y (2007) Investigation on the immunoregulation functions of Zhuyeqing Liquor. Liq Making Sci Technol 2:117-119

Hòrie T, Ohtsuru Y, Shibata K, Yamashita K, Tsukayama M, Kawamura Y $(1998){ }^{13} \mathrm{C}$ NMR spectral assignment of the a-ring of polyoxygenated flavones. Phytochemistry 47:865-874

Huang Y, Chang RJ, Jin HZ, Zhang WD (2012) Phenolic constituents from Tsoongiodendron odorum chun. Tianran Chanwu Yanjiu Yu Kaifa 24:176-178

Ke Y, Jiang Y, Luo SQ (1999) Chemical constituents from Clinopodium chinense (Benth.) O. Ktze. Chin Traditional Herbal Drugs 30:8-10

Kumarasamy Y, Byres M, Cox PJ, Delazar A, Jaspars M, Nahar L, Shoeb M, Sarker SD (2004) Isolation, structure elutiondition, and biological activity of flavone 6-C-glycosides from Alliaria petiolata. Chem Nat Compd 40:122-128

Lin LB, Fu XW, Al CH, Shen J, Wei K, Li W (2006) Studies on chemical constituents in leaves of Mallotus furetianus. China J Chin Materia Medica 31:477-479

Liu XM, Jiang Y, Sun YQ, Xu XW, Tu PF (2011) Chemical constituent study of Herba Cistanches. Chin J Pharm 46:1053-1058

Ma ZT, Yang XW, Zhong GY (2009) A new flavonoid glucoside from Huanglian jiedutang decoction. China J Chin Materia Medica 34:1097-1100

Miyake Y, Mochizuki M, Okada M, Hiramitsu M, Morimitsu Y, Osawa T (2007) Isolation of antioxidative phenolic glucosides from lemon juice and their suppressive effect on the expression of blood adhesion molecules. Biosci Biotech Biochem 71:1911-1919

Okamura N, Hine N, Tateyama Y, Nakazawa M, Fujioka T, Mihashi K, Yagi A (1998) Five chromones from Aloe vera leaves. Phytochemistry 49:219-223

Rayyan S, Fossen T, Solheim Nateland H, Andersen ØM (2005) Isolation and identification of flavonoids, including flavone rotamers, from the herbal drug 'crataegi folium cum flore' (hawthorn). Phytochem Anal 16:334-341

Wang QJ, Wang YS, He L, Lou ZP, Zang S (2010) Study on chemical constituents from Ipomoea Pescaprae (L.) Sweet. Chin J Marine Drugs 29:41-44

Yang HP (2007) Zhuyeqing liquor in different historical period. Liquor Making Sci Technol 2:110-112

Yoo SW, Kim JS, Kang SS, Son KH, Chang HW, Kim HP, Bae KH, Lee CO (2002) Constituents of the fruits and leaves of Euodia daniellii. Arch Pharm Res 25:824-830

Zhang YW, Chen YW (1997) Isobiflorin, a chromone C-glucoside from cloves (Eugenia Caryophyllata). Phytochemistry 45:401-403

doi:10.1186/s40543-014-0034-

Cite this article as: Gao et al:: Simultaneous quantification of major bioactive constituents from Zhuyeqing Liquor by HPLC-PDA. Journal of Analytical Science and Technology 2014 5:34. 